\title{
BMJ
}

\section{Community occupational therapy for older patients with dementia and their care givers: cost effectiveness study}

\author{
Maud I L Graff, scientific researcher in allied healthcare research, ${ }^{1,3}$ Eddy M M Adang, senior researcher in \\ efficiency studies, ${ }^{2}$ Myrra J M Vernooij-Dassen, professor in psychosocial aspects of care for frail elderly, ${ }^{3}$ \\ Joost Dekker, professor in allied health care, ${ }^{4} \mathrm{~L}$ Jönsson, senior researcher in health economic studies, ${ }^{5}$ \\ Marjolein Thijssen, research assistant, ${ }^{1,3}$ Willibrord H L Hoefnagels, professor in geriatrics, ${ }^{6}$ \\ Marcel G M Olde Rikkert, professor in geriatrics ${ }^{6}$
}

${ }^{1}$ Alzheimer Centre Nijmegen, Department of Occupational Therapy 897, Radboud University Nijmegen Medical Centre,

PO Box 9101, 6500 HB Nijmegen, Netherlands

${ }^{2}$ Department of Epidemiology, Biostatistics and Health

Technology Assessment, Radboud University Nijmegen Medical

Centre

${ }^{3}$ Alzheimer Centre Nijmegen, Department of Quality of Care Research, Radboud University Nijmegen Medical Centre

${ }^{4}$ Department of Rehabilitation Medicine, Free University Medical Centre Amsterdam, Amsterdam, Netherlands

${ }^{5}$ Division of Geriatric Epidemiology, Neurotec Department, Karolinska Institute, Stockholm, Sweden

${ }^{6}$ Alzheimer Centre Nijmegen, Department of Geriatrics 925, Radboud University Nijmegen Medical Centre

Correspondence to: M J L Graff m.graff@pmd.umcn.nl

doi:10.1136/bmj.39408.481898.BE

\section{ABSTRACT}

Objective To assess the cost effectiveness of community based occupational therapy compared with usual care in older patients with dementia and their care givers from a societal viewpoint.

Design Cost effectiveness study alongside a single blind randomised controlled trial.

Setting Memory clinic, day clinic of a geriatrics department, and participants' homes.

Patients 135 patients aged $\geq 65$ with mild to moderate dementia living in the community and their primary care givers.

Intervention 10 sessions of occupational therapy over five weeks, including cognitive and behavioural interventions, to train patients in the use of aids to compensate for cognitive decline and care givers in coping behaviours and supervision.

Main outcome measures Incremental cost effectiveness ratio expressed as the difference in mean total care costs per successful treatment (that is, a combined patient and care giver outcome measure of clinically relevant improvement on process, performance, and competence scales) at three months after randomisation. Bootstrap methods used to determine confidence intervals for these measures.

Results The intervention cost $€ 1183(£ 848, \$ 1738)(95 \%$ confidence interval $€ 1128$ ( $£ 808, \$ 1657)$ to $€ 1239$ ( $£ 888$, $\$ 1820)$ ) per patient and primary care giver unit at three months. Visits to general practitioners and hospital doctors cost the same in both groups but total mean costs were $€ 1748$ ( $£ 1279$, \$2621) lower in the intervention group, with the main cost savings in informal care. There was a significant difference in proportions of successful treatments of $36 \%$ at three months. The number needed to treat for successful treatment at three months was 2.8 (2.7 to 2.9 ).

Conclusions Community occupational therapy intervention for patients with dementia and their care givers is successful and cost effective, especially in terms of informal care giving.

\section{INTRODUCTION}

Dementia is one of the three major diseases with regard to healthcare consumption ${ }^{1-4}$ and is a major cause of disability and burden of care in elderly people. ${ }^{5}$ Dementia is a chronic and degenerative disease that causes disorders of memory, behavioural problems, loss of initiative, loss of independent functioning in daily activities, and loss of participation in social activities. These problems decrease wellbeing of those with dementia and their care givers, ${ }^{6}$ put pressure on family relationships and friendships, ${ }^{7-10}$ and cause high healthcare costs. The world prevalence of dementia has recently been estimated at 24.3 million people. This is expected to double over the next 20 years. ${ }^{11}$ In 2002, in the Netherlands alone, nearly $1 \%$ of people aged 65 had dementia. This percentage rose with increasing age to around $40 \%$ in people aged 90 and over. By 2050 it is predicted that $2.2 \%$ of 65 year olds will have dementia. ${ }^{12}$

In the Netherlands in 2003, 5.3\% of the total healthcare budget was spent on dementia, which was $14 \%$ of the age specific total costs for people aged 75-84 and $22 \%$ for people aged 85 and older. ${ }^{13}$ Because of an ageing population, the numbers of patients and the related healthcare costs will increase substantially in the next five decades. ${ }^{2412}$ Healthcare costs in the Netherlands are predicted to rise from $€ 57 \mathrm{bn}(£ 41 \mathrm{bn}$, $\$ 84 \mathrm{bn})$ in 2003 to $€ 70$ bn $(£ 50, \$ 103)$ in 2025 , and $€ 10 \mathrm{bn}$ ( $£ 7 \mathrm{bn}, \$ 15 \mathrm{bn}$ ) of this increase will be caused by the "greying population" and related diseases such as dementia. ${ }^{14}$ In the Netherlands in 2002, 39\% of people with dementia needed continuous care, 38\% needed home care daily, $23 \%$ needed home care occasionally, and $60 \%$ of those living in the community needed daily or continuous care. ${ }^{15}$

In Scandinavia, informal care costs, valued at the opportunity costs of the care giver's time, made up about a third of the total annual costs in dementia and increased considerably with severity of disease. ${ }^{5}$ It is therefore important to implement new effective and efficient healthcare interventions that increase independence and wellbeing of the patients and decrease 
the burden on care givers, resulting in a more efficient use of scarce healthcare resources. ${ }^{16}$

Occupational therapy can improve daily functioning, social participation, and wellbeing in people with dementia living in the community and improve the sense of competence and wellbeing of their primary care givers. ${ }^{6917-20}$ It might reduce healthcare costs because of improved independence in patients and improved sense of competence in care givers, which might result in lower costs of informal care, delayed admission to nursing homes, and lower costs of other healthcare and social services-for example, costs for day care, home care, or meals on wheels. Occupational therapy is not usually recommended for patients with dementia in primary health care. Recent research has looked at the efficacy and effectiveness of community occupational therapy in patients with dementia and their primary care givers. ${ }^{6917182021}$ In one study of an efficient preventive nine month occupational therapy programme there was a trend towards lower medical costs and more independent living. ${ }^{22}$ In a cost effectiveness study of cognitive stimulation therapy in patients with dementia, Knapp and colleagues concluded that it was cost effective because it has benefits on cognition and quality of life and has no adjuvant costs compared with usual care. ${ }^{23}$ Melis et al reported effectiveness of a multidisciplinary home based intervention for frail older people on prevention of functional decline and improved wellbeing for reasonable costs. ${ }^{24}$ Brodaty and Peters found that an intensive 10 day training programme for care givers was cost effective as it saved $\$ 5975$ per patient in 39 months and was associated with patients being able to live at home for longer and decreased psychological morbidity in care givers. $^{25}$

We determined the cost effectiveness of community occupational therapy for people with dementia and their primary care givers compared with usual care from a societal viewpoint. We chose a societal viewpoint because primary care givers spend many hours on care for their relatives and this intervention ${ }^{6920}$ aimed at decreasing patients' need for assistance and improving supervision skills in care givers. Usual care means the care dementia patients and care givers usually receive (without this new community occupational therapy intervention).

\section{METHODS}

\section{Participants}

From April 2001 to January 2005, we recruited people with dementia and their care givers from the memory clinic and the day clinic of a department of geriatrics. Patients were included if they were aged 65 or over, had been diagnosed with mild to moderate dementia, were living in the community, and had a primary care giver who cared for them at least once a week. The diagnosis of dementia was based on criteria from the Diagnostic and Statistical Manual of Mental Disorders, fourth edition. ${ }^{26}$ Severity of dementia was determined with the brief cognitive rating scale (BCRS), ${ }^{27}$ with a score of 9-24 indicating mild dementia and a score of 25-40

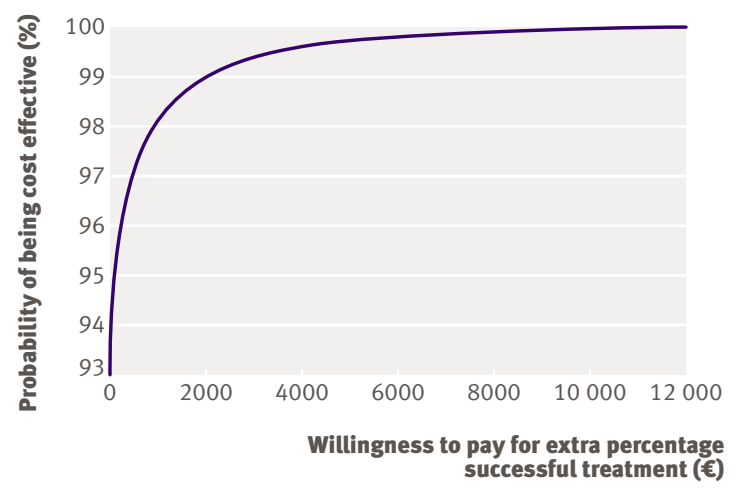

Cost effectiveness acceptability curve of community occupational therapy compared with usual care

indicating moderate dementia. We excluded patients with a score $>12$ on the geriatric depression scale $(30$ items), ${ }^{28}$ severe behavioural or psychological symptoms in dementia (BPSD), and severe illnesses as judged by a geriatrician and those in whom goals of occupational therapy could not be defined or who were not on stable treatment of a dementia drug (that is, less than three months on the same dose of a cholinesterase inhibitor or memantine). We also excluded care givers with severe illnesses. Detailed description of the participants has been published elsewhere. ${ }^{9}$

\section{Randomisation and procedures}

Patients were randomly assigned by blocked randomisation (block size of four) to the intervention (10 sessions of occupational therapy at home over five weeks) or control group (usual care with no occupational therapy), which was stratified by level of dementia (mild or moderate). A statistician not involved in the study carried out randomisation. Concealed envelopes were used to allocate the patients and these envelopes were opened by an independent secretary. Patients and care givers were aware of the treatment assigned. The assessors (MT or MJLG) were blinded to group allocation. Patients and care givers were asked before each assessment not to inform the assessors about the intervention. To check the success or failure of the blinding after each measurement the assessors were asked if they had been told or knew for sure to which group each patient had been allocated. The total study period per patient was three months from the moment of inclusion. The control group received occupational therapy after completion of the study (three months later). Detailed description of randomisation and procedures has been published elsewhere. $^{9}$

\section{Intervention}

The study intervention was developed in a consensus process $^{29}$ and was implemented by experienced occupational therapists who had been trained (80 hours) and were experienced (at least 240 hours) in delivering treatment according to this client centred occupational therapy guideline for patients with 
dementia ${ }^{6910}$ Treatment consisted of 10 one hour sessions held over five weeks and focused on both patients and their primary care givers. In the first four sessions of diagnostics and goal defining, patients and primary care givers learnt to define their problems and choose and prioritise meaningful activities they wanted to improve. To this end, the occupational therapists used three client centred narrative interview instruments. The occupational therapist evaluated the possibilities for modifying the patient's home and environment and observed the patient's ability to perform relevant daily activities and to use compensatory and environmental strategies. Compensatory strategies are used to adapt activities of daily living to the disabilities of patients, and environmental strategies are used to adapt the patients' environment to their cognitive disabilities. The therapist also observed primary care givers' abilities and supervision skills.

In the remaining six sessions, patients were taught to optimise these compensatory and environmental strategies to improve their performance of daily activities. Primary care givers were trained, by means of cognitive and behavioural interventions, to use effective supervision, problem solving, and coping strategies to sustain patients' and their own autonomy and social participation.
The total time spent for the intervention, including the time spent for treatment at home (10 hours), narrative analysis, reports, and multidisciplinary briefing was about 18 hours per patient and care giver together. More detailed description of the intervention has been published elsewhere. ${ }^{10}$

\section{Outcome assessments of effects}

We assessed patients and their primary care givers at baseline before the intervention and six weeks and three months later. Our primary outcome measure for patients was daily functioning assessed with the process scale of the assessment of motor and process skills, ${ }^{30}$ in which scores range from -3 to 4 (higher scores indicate better process skills), and with the performance scale of the interview of deterioration in daily activities in dementia, ${ }^{31}$ in which scores range from 0 to 44 (lower scores indicate less need for assistance). The primary outcome for care givers was assessed with the sense of competence questionnaire, ${ }^{32}$ in which scores ranged from 27 to 135 (higher scores denote greater sense of competence).

Over a three month period these three primary outcomes were combined in one measure for successful treatment outcome for the economic evaluation. Successful outcome was defined as a clinically relevant

Table 1 Demographic characteristics and outcome measures of elderly people with dementia and their care givers according to allocation at enrolment. Figures are numbers of participants unless stated otherwise

\begin{tabular}{|c|c|c|}
\hline & Occupational therapy $(n=68)$ & Usual care $(n=67)$ \\
\hline \multicolumn{3}{|l|}{ Mean (SD) age (years): } \\
\hline Patient & $79.1(6.2)$ & $77.1(6.3)$ \\
\hline Primary care giver & $66.0(15.3)$ & $61.3(15.4)$ \\
\hline \multicolumn{3}{|l|}{ Sex (M/F): } \\
\hline Patient & $29 / 39$ & $31 / 36$ \\
\hline Primary care giver & $22 / 46$ & $18 / 49$ \\
\hline \multicolumn{3}{|l|}{ Relation care giver to patient: } \\
\hline Partner & 41 & 38 \\
\hline Daughter & 22 & 21 \\
\hline Other & 5 & 8 \\
\hline \multicolumn{3}{|l|}{ Mean (SD) scores } \\
\hline Domestic home care & $11.6(26.3)$ & $16.5(41.0)$ \\
\hline Nurse home care & $24.2(42.2)$ & $24.4(47.1)$ \\
\hline Mini-mental state examination & $19.0(5.7)$ & $19.0(4.0)$ \\
\hline CIRS-G & $10.7(3.5)$ & $11.6(4.3)$ \\
\hline Geriatric depression scale & $6.9(3.0)$ & $7.5(3.0)$ \\
\hline RMBPC-frequency & $5.6(5.3)$ & $5.0(6.0)$ \\
\hline AMPS-process & $0.2(0.8)$ & $0.3(0.8)$ \\
\hline IDDD-performance & $23.5(7.9)$ & $24.5(8.7)$ \\
\hline Cornell depression scale & $8.3(6.2)$ & $8.1(4.6)$ \\
\hline Brief cognitive rating scale & $27.3(5.1)$ & $27.1(4.2)$ \\
\hline Sense of competence & $89.7(14.9)$ & $90.4(13.6)$ \\
\hline CES-D & $11.7(8.3)$ & $11.4(7.2)$ \\
\hline \multicolumn{3}{|c|}{$\begin{array}{l}\text { Mini-mental state examination: measures mental state/cognitive functioning; CIRS-G=cumulative illness rating scale for geriatrics, measures } \\
\text { comorbidity ( } 14 \text { items, score } 14-56) \text {; geriatric depression scale: diagnostic scale, measures depressive complaints of the patient ( } 30 \text { items, score } 0 \text { - } \\
30) \text {; RMBPC=revised memory and behavioural problems checklist, measures memory and behavioural problems ( } 24 \text { items, score } 0-96) \text {; } \\
\text { AMPS=assessment of motor and process skills-process scale, measures process skills }(21 \text { items, score }-3-4) \text {; IDDD=interview of deterioration in daily } \\
\text { activities in dementia-performance scale, measures need for assistance ( } 11 \text { items, score } 0-44) \text {; Cornell scale for depression-frequency scale, sensitive } \\
\text { instrument measures frequency of depressive complaints of patient over longer time }(19 \text { items, score } 0-38) \text {; BCRS=brief cognitive rating scale }(8 \text { items, } \\
\text { score } 8-56) \text {; sense of competence questionnaire (SCQ), measures sense of competence }(27 \text { items, score } 27-135) \text {; CES-D=Centre for Epidemiologic } \\
\text { Studies depression scale, measures depressive complaints of care giver ( } 20 \text { items, score } 0-60) \text {. }\end{array}$} \\
\hline
\end{tabular}


Table 2 | Mean (SD) number of healthcare units used per patient during three months of follow-up

\begin{tabular}{|c|c|c|}
\hline & Occupational therapy $(n=67)$ & Usual care $(n=65)$ \\
\hline OT home visits & $9.3(1.8)$ & 0 \\
\hline $\begin{array}{l}\text { OT additional hours (telephone contacts, reports, written } \\
\text { advice) }\end{array}$ & $7.4(1.4)$ & 0 \\
\hline Physiotherapy visits & $3.4(6.5)$ & $4.2(8.1)$ \\
\hline Social worker visits & $0.8(2.1)$ & $1.0(2.7)$ \\
\hline General practitioner visits & $0.1(0.5)$ & $0.2(0.8)$ \\
\hline Hospital specialist visits & $0.2(0.8)$ & $0.2(0.8)$ \\
\hline Nursing home care (hours) & $47.7(79.2)$ & $37.4(61.1)$ \\
\hline Domestic home care (hours) & $19.0(45.6)$ & $23.2(48.7)$ \\
\hline Day care (days) & $3.4(9.7)$ & $5.0(10.7)$ \\
\hline Meals on wheels (days) & $14.9(30.3)$ & $15.8(30.9)$ \\
\hline Admission to hospital (days) & $1.6(6.8)$ & $2.1(8.6)$ \\
\hline \multicolumn{3}{|l|}{ Admission to institution (days): } \\
\hline Nursing home & $1.6(7.9)$ & $2.4(13.3)$ \\
\hline Home for elderly & $0.8(6.8)$ & $0.9(6.9)$ \\
\hline Informal care (hours) & $913.5(666.5)$ & $1125.8(830.2)$ \\
\hline
\end{tabular}

improvement in patients and care givers for all three primary outcome measures (process scale, performance scale, and competence scale). This means that the treatment was judged successful if the process, performance, and competence scale scores showed improvements of $\geq 0.5$ points, $\geq 20 \%$, and $\geq 5$ points, respectively; the criteria for clinical significance. ${ }^{30-32}$

Demographic characteristics and outcome measures collected at baseline included information on the age, sex, and educational level of the patient and care giver, and information on patients' comorbidity (assessed with the cumulative illness rating scale for geriatrics ${ }^{33}$ ), depressive mood (assessed with the geriatric depression scale ${ }^{28}$ ), cognition (assessed with the brief cognitive rating scale ${ }^{27}$ ), and behaviour (assessed with the revised memory and behavioural problems checklist $\left.^{3435}\right)$. For each carer we also collected information on the relationship to the patient and depression (assessed with the centre for epidemiologic depression scale $\left.^{36}\right)$.

\section{Cost analysis}

We evaluated costs from a societal viewpoint and included both direct costs inside and outside the healthcare service and indirect costs outside the healthcare service. This societal viewpoint includes all costs our society met as a consequence of this community occupational therapy ${ }^{37}$ and thus includes not only the costs of healthcare services delivered by different healthcare workers but also the estimated costs for gains and losses in productivity of the care givers. ${ }^{38}$ Because the study lasted only three months we did not expect a discount effect and therefore did not correct for inflation. We performed an incremental analysis in which we analysed in detail only costs that potentially differed between the two groups.

We used several instruments to measure the consumed resources. The primary care givers kept a diary to record the patients' visits to the general practitioner, physiotherapist, social worker, or other healthcare suppliers specifically related to the dementia. Care givers also used these diaries to register their own visits to healthcare services if they had physical or emotional health complaints and their hours spent on care for their relatives (or friends or neighbours). They recorded the number of hours the patients received care at home from a nurse or a housekeeper or day care and if they received other services like meals on wheels. Finally, they noted the days of illness in the patients and the number of days patients had spent in day care or were admitted to hospital, nursing homes, or homes for the elderly. Three diaries were handed out. At six and 12 weeks the researchers received the diary that was filled in by the primary care givers in the previous six weeks. At baseline, care givers filled in a diary for the past six weeks retrospectively.

The quantities measured were multiplied by unit costs (prices) to obtain the costs involved. The costs for community occupational therapy sessions were based on outpatient price for employee costs (this is, a defined price for outpatient occupational therapy per hour), and additional costs for home visits, and travelling costs (distance multiplied by price per kilometre)..$^{39}$ The additional costs of occupational therapy (hours of administration and analysis of interview data, reports, advice, and multidisciplinary briefing) were based on the employee costs per hour. We used these figures to compute standard prices for occupational therapy home visits and for additional hours spent by the occupational therapist. We based prices for visits to the general practitioner, day care, home care or household support, and other resources, such as visits to the physiotherapist, on Dutch guidelines for economic health care ${ }^{38}$ Costs for the hospital social worker and hospital physician were calculated from the employee costs multiplied by a percentage of $39 \%$ for employer premiums as social taxes, holidays, and employee facilities. Hours invested by care givers were counted 
according to Dutch guidelines, which reflect an average of costs for care givers still in paid employment and care givers not working any more. These costs for informal care giving are computed according to the "friction cost method" in which a price for care giving in general is computed based on hours of absence because of care giving or illnesses of the care givers and which is valued at an hourly wage of a middle aged cleaning person of $€ 8(£ 6, \$ 12)$ an hour. ${ }^{38}$

\section{Statistical analysis}

We analysed differences in outcome by analyses of covariance of the primary outcome measures (process scale of the assessment of motor and process skills, performance scale of the interview of deterioration in daily activities, and competence scale assessed by the sense of competence questionnaire at three months) based on an intention to treat analysis of all available data and carrying forward the last observation for drop outs and those with missing data. Participants with missing data at baseline were not included in the analyses as in the randomised controlled trial. ${ }^{9}$ The covariates were age, sex, relationship between the patient and the care giver, other care givers, and baseline scores for cognitive functioning on the minimental state examination (score 10-24 for mild to moderate dementia), ${ }^{26}$ depression assessed with the geriatric depression scale (30 items), ${ }^{28}$ comorbidity assessed with the cumulative illness rating scale for geriatrics, ${ }^{34}$ behaviour assessed with the revised memory and behavioural problems checklist, ${ }^{3435}$ and the outcome variable.

The study was powered to detect a clinically relevant difference in change between the groups over time of 0.5 points on the process scale, ${ }^{30} 20 \%$ improvement on the performance scale, ${ }^{31}$ and a 5 point difference on the competence scale, ${ }^{32}$ with a power of $80 \%$ on the basis of one sided testing, a standard deviation of 0.8 on the process scale, and $n \geq 100$. The power calculation was based on earlier data ${ }^{20}$ and on the minimal clinically relevant differences in the primary outcomes. ${ }^{3031}$

We computed the proportion of patients and care givers achieving a clinically relevant improvement for each of the primary outcome measures separately and for all three together, which was the fraction with successful treatment outcome. We calculated the difference in treatment effect as the difference in successfully treated patients and care givers combined. Incremental treatment costs were calculated as the difference in mean total care costs. We replaced missing values in quantities of care with series means. Based on the differences in mean total costs between the groups, and the change in outcome measure, we calculated an incremental cost effectiveness ratio, which was expressed as total costs per successful treatment. Bootstrap methods were used to explore the uncertainty in the estimates of cost effectiveness and determine confidence intervals.

We used one way sensitivity analyses to examine the robustness of the findings of the cost effectiveness analysis. In the cost analysis, we calculated prices for occupational therapy, other healthcare resources, and care giving by primary care givers during follow-up and performed a sensitivity analysis on these figures. We assessed cost effectiveness graphically with an acceptability curve to summarise the evidence in support of the intervention being cost effective compared with usual care for all potential values of the willingness to pay per patient-care giver unit per successful treatment.

\section{RESULTS}

Effects

We evaluated 275 people with dementia who were living in the community. Of the 135 eligible patients randomised, three (one in the intervention group, two in the control group) with their care givers stopped the trial immediately after randomisation because they did not want to continue and they did not receive the study intervention. This left 132 patients with care givers for the intention to treat analysis ${ }^{9}$ and the cost effectiveness analysis.

The baseline characteristics of patients and care givers were well matched between the two groups (table 1). Age differences (patients and their primary care givers were 2.0 and 4.7 years younger in the control group) were corrected in the analysis of covariance. Socioeconomic status was equally divided

Table 3 | Effect of treatment and mean (SD) costs per patient at three month follow-up

\begin{tabular}{|c|c|c|c|}
\hline & Occupational therapy $(n=67)$ & Usual care $(n=65)$ & Difference $(95 \% \mathrm{Cl})$ \\
\hline \multicolumn{4}{|l|}{ Effect } \\
\hline No (\%) of "successful treatments" & $25(37)$ & $1(1.5)$ & $36 \%(23 \%$ to $47 \%)$ \\
\hline No with missing data & 1 & 2 & - \\
\hline NNT $(95 \% \mathrm{Cl})$ & 2.8 (2.7 to 2.9$)$ & - & - \\
\hline \multicolumn{4}{|l|}{ Costs $(€)^{\star}$} \\
\hline Total care costs & $12563(6628)$ & $14311(7833)$ & $-1748(-4244$ to 748$)$ \\
\hline \multicolumn{4}{|l|}{ Intervention (OT): } \\
\hline Visits & 774 (151) & 0 & 774 (737 to 810$)$ \\
\hline Additional & $409(78)$ & 0 & 409 (391 to 429) \\
\hline Total & $1183(228)$ & 0 & 1183 (1128 to 1239$)$ \\
\hline
\end{tabular}


over the groups. The occupational therapist visited those in the intervention group an average of nine times at home for one hour and spent an additional seven hours (time for administration and analysis of interview data, reports, advice, and multidisciplinary briefing) per patient and care giver couple (table 2).

At three months 53 of the 68 patients in the intervention group and 52 of the 67 in the control group remained in the study and these were the same participants as in the effectiveness study. ${ }^{9}$

We used intention to treat analysis $(n=132)$, with the last observation carried forward, to analyse the effects in both groups. There were significant differences between the groups on all primary outcome variables at three months. In the intention to treat analysis $(n=132)$, treatment was considered as successful (clinically relevant and significant improvement on all three outcome measures of patients' daily functioning and care givers' sense of competence) in 26 patients and their care givers, of whom $25(37 \%)$ were in the intervention group $(\mathrm{n}=67)$ and one $(1.5 \%)$ was in the control group $(n=65)$. The number needed to treat for a successful treatment outcome was 2.8 (95\% confidence interval 2.7 to 2.9 ) (table 3 ). No adverse events were reported in either group.

\section{Costs}

The occupational therapy intervention cost $€ 1183$ (£848, \$1738) per patient and care giver couple $(95 \%$ confidence interval $€ 1128$ to $€ 1239$ ) (table 4). The usual care group received no occupational therapy. The costs for visits to a general practitioner and hospital doctor were equal in both groups. Costs for other health care, such as nursing home care $(-€ 417)$, domestic home care $(-€ 91)$, social worker $(-€ 8)$, and physiotherapist ($€ 36)$, day care $(-€ 197)$, and meals on wheels $(-€ 8)$ were

\begin{tabular}{|c|c|c|c|}
\hline & Occupational therapy $(n=67)$ & Usual care $(n=65)$ & Difference in cost $(95 \% \mathrm{Cl})$ \\
\hline \multicolumn{4}{|l|}{ Physiotherapy: } \\
\hline Average cost* & $152(290)$ & $188(363)$ & $-36(-149$ to 77$)$ \\
\hline No (\%) who used service & $27(40)$ & $18(28)$ & - \\
\hline Costs if used $\dagger$ & 377 & 679 & - \\
\hline \multicolumn{4}{|l|}{ Social worker: } \\
\hline Average cost* & $26(68)$ & $34(90)$ & $-8(-35$ to 20$)$ \\
\hline No (\%) who used service & $11(16.9)$ & $13(20)$ & - \\
\hline Costs if used $\dagger$ & 158 & 170 & - \\
\hline \multicolumn{4}{|l|}{ General practitioner: } \\
\hline Average cost* & $3(11)$ & $3(17)$ & $0(-5$ to 4$)$ \\
\hline No (\%) who used service & $5(7.5)$ & $3(4.6)$ & - \\
\hline Costs if used $\dagger$ & 40 & 65 & - \\
\hline \multicolumn{4}{|l|}{ Hospital specialist: } \\
\hline Average cost* & $5(16)$ & $4(16)$ & $1(-5$ to 6$)$ \\
\hline No (\%) who used service & $6(9)$ & $5(7.6)$ & - \\
\hline Costs if used $\dagger$ & 56 & 52 & - \\
\hline \multicolumn{4}{|l|}{ Nurse home care: } \\
\hline Average cost* & $1512(2469)$ & $1929(3201)$ & $-417(-1399$ to 566$)$ \\
\hline No (\%) who used service & $40(59.7)$ & $33(50.8)$ & - \\
\hline Costs if used $\dagger$ & 2533 & 3800 & - \\
\hline \multicolumn{4}{|l|}{ Domestic home care: } \\
\hline Average cost* & $413(990)$ & $504(1056)$ & $-91(-443$ to 262$)$ \\
\hline No (\%) who used service & $26(38.8)$ & $29(44.6)$ & - \\
\hline Costs if used $\dagger$ & 1064 & 1130 & - \\
\hline \multicolumn{4}{|l|}{ Day care: } \\
\hline Average cost* & $408(1178)$ & $605(1291)$ & $-197(-622$ to 228$)$ \\
\hline No (\%) who used service & $9(13.4)$ & $17(26.2)$ & - \\
\hline Costs if used $\dagger$ & 3037 & 2513 & - \\
\hline \multicolumn{4}{|l|}{ Meals-on-wheels: } \\
\hline Average cost* & $134(273)$ & $142(278)$ & $-8(-103$ to 87$)$ \\
\hline No (\%) who used service & $14(20.9)$ & $16(24.6)$ & - \\
\hline Costs if used $\dagger$ & 641 & 577 & - \\
\hline \multicolumn{4}{|l|}{ Admitted to hospital: } \\
\hline Average cost* $^{\star}$ & 739 (3215) & $981(4114)$ & $-242(-1512$ to 1027$)$ \\
\hline No (\%) who used service & $6(9.0)$ & $7(10.8)$ & - \\
\hline Costs if used $\dagger$ & 8252 & 9109 & - \\
\hline
\end{tabular}


Table 5 | Effect of treatment on admission to institution at three month follow-up. Figures are mean (SD) costs ( $€$ ) per patient

\begin{tabular}{|c|c|c|c|}
\hline Admission to institution & Occupational therapy $(n=67)$ & Usual care $(n=65)$ & Difference in cost $(95 \% \mathrm{Cl})$ \\
\hline \multicolumn{4}{|l|}{ Nursing home: } \\
\hline Average cost* ${ }^{\star}$ & 335 (1635) & $501(2731)$ & $-166(-938$ to 607$)$ \\
\hline No (\%) who used service & $5(7.5)$ & $5(7.7)$ & - \\
\hline Costs if used $\dagger$ & 4489 & 6513 & - \\
\hline \multicolumn{4}{|l|}{ Home for elderly: } \\
\hline Average cost $^{\star}$ & $71(582)$ & $77(590)$ & $-6(-208$ to 196$)$ \\
\hline No (\%) who used service & $1(1.5)$ & $4(6.2)$ & - \\
\hline Costs if used $\dagger$ & 4757 & 1251 & - \\
\hline \multicolumn{4}{|l|}{ Informal care: } \\
\hline Average cost & 7582 & 9344 & $-1762(-3919$ to 395$)$ \\
\hline No (\%) who used service & $67(100)$ & $65(100)$ & - \\
\hline Costs if used $\dagger$ & 7582 & 9344 & - \\
\hline
\end{tabular}

*Costs per patient averaged over all patients in each group.

†Costs of specific service when averaged over those patients who actually used it.

all lower in the intervention group (table 4), as were costs for admission to hospital $(-€ 242)$ and nursing homes and homes for the elderly $(-€ 172)$ (table 5$)$. The main cost savings were from reduced informal care in the intervention group $(-€ 1762)$ (table 5).

The economic evaluation showed average savings of $€ 1748$ (£1279, \$2621) per couple successfully treated with occupational therapy. The probability of occupational therapy being the dominant intervention was estimated to be $94 \%$ (figure). The acceptability curve shows, when interpreted in a Bayesian sense, that if society is willing to pay $€ 2000$ (£1469, \$2933) or more for a successful treatment then there is $99 \%$ probability that occupational therapy is efficient (figure).

\section{DISCUSSION}

Community occupational therapy intervention for people with dementia and their primary care givers is cost effective, at a cost of about $€ 1200(£ 859, \$ 1790)$ per patient and care giverover a three month period. The intervention was associated with a $35 \%$ higher proportion of successful treatment. The mean costs per patient and care giver of all care for the three months were $€ 12563$ (£8994, \$18433) for the intervention group and $€ 14311$ ( $£ 10246, \$ 20998$ ) for the control group. This means that from a societal viewpoint community occupational therapy is an effective and efficient intervention strategy. It is cost effective because on average it saved $€ 1748(£ 1279, \$ 2641)$ over three months (with a probability of 95\%), and yielded significant and clinically relevant improvements in daily functioning in patients and sense of competence in care givers.

\section{Relevance of results}

Comparison of our results with others is difficult because of the lack of similar studies. Hay et al looked at cost effectiveness of a preventive occupational therapy for independent living older adults in a randomised controlled trial with an occupational therapy group, a social activity group, and a control with no treatment. ${ }^{22}$ The costs for the nine month preventive occupational therapy programme ( $\$ 548$ per person) and the followup costs at 15 months for the occupational therapy group (\$967) were lower than for the social activity group (\$1726) and the control (\$3334). The authors concluded that the programme was cost effective and showed a trend towards decreased medical expenditures. The estimated cost per quality adjusted life year (QALY) for the occupational therapy group were \$ 10666 per group of about 55 patients.

\section{Strengths and limitations}

Our study was empirically robust because we used a randomised controlled design and carried out the economic analysis from a societal perspective. Another strong point is the new outcome measure "successful treatment outcome" that we used as the primary outcome in this cost effectiveness analysis. This outcome measure is innovative and combines the effect of occupational therapy on outcome in both patient and care giver, which represents the whole content and outcome of successful occupational therapy treatment.

We did not include a generic measure for quality of life on which QALYs could be computed, which limits comparability with other interventions. QALYs are, according to most guidelines on cost effectiveness, the principal measure of effect in economic analyses. Mostly this is because there are reference values for "willingness to pay for QALYs," which is important when costs need to be traded off against effects. In our particular case, however, in which the experimental treatment is dominant (lower costs and more effects), there is no trade off between costs and effects. Moreover, given the results (an average cost saving and a $95 \%$ probability of being the dominant strategy) the conclusion that occupational therapy is cost effective would not be altered if we included quality of life as an outcome measure.

A second limitation of our study design is that, as with some other types of treatment, we could not carry out a double blind study because the patients and their care givers and the occupational therapists could not be 


\section{WHAT IS ALREADY KNOWN ON THIS TOPIC}

Community occupational therapy improves daily functioning in patients with dementia and reduces the burden on care givers

Dementia is categorised as one of the three major diseases in healthcare costs and is a major cause of disability and burden of care in elderly people

\section{WHAT THIS STUDY ADDS}

Community occupational therapy intervention is cost effective and specifically reduces costs of informal care giving professional home care worker. Though home care workers are trained, training does not extend to occupational therapy but this would probably result in a more effective care strategy resulting in even higher savings. We will investigate this in a future study on the effectiveness of a national implementation policy of our guideline. We also expect that it would be helpful if home care workers were educated to supervise care givers in continuing their effective way of care giving at home several months after the intervention ends. It also would be interesting to investigate whether home care workers with special training in occupational therapy would be able to deliver part of the occupational therapy under supervision of occupational therapists.

blinded to allocation. We tried to maintain masked conditions when possible when it came to assessment, which succeeded for $80 \%$ of the cases. ${ }^{40}$ For this reason, we believe that our results are not significantly affected by observer bias.

The study took place over a relatively short time, with a three month follow-up. ${ }^{37}$ Based on the remaining effects on the primary outcomes of the randomised controlled trial at three months, ${ }^{9}$ however, we expect that the savings at six months would be even greater, with no more costs incurred. In future studies the effectiveness, and consequently its cost effectiveness, should be assessed to determine if effects indeed remain over time.

Our participants might not be representative of all patients with mild to moderate dementia in our health region as they were recruited primarily from the outpatient clinics of the university hospital and not from other institutions or directly from general practices. We chose this recruitment strategy because we wanted to achieve uniformity in terms of screening and diagnosis of dementia to facilitate comparison with other national and international studies. Our participants were also not representative of all older people with mild to moderate dementia living in the community because we excluded those who lived alone. The groups might be comparable on socioeconomic status because the whole range of educational levels and former and recent occupations was representative of the general population. Another issue is the costs for informal care giving, which were computed with the "friction cost method. ${ }^{38}$ In our study most of the care givers were retired. If other informal care givers had been used (for example, more employed sons and daughters or neighbours) another value would have been plausible. We assumed that medical costs did not increase because of the short time window. ${ }^{22}$ According to that study we have underestimated the potential medical savings associated with our intervention.

Ethical questions can be raised about the exclusion of individuals from this highly effective and efficient intervention. However, it was not previously recommended in the Netherlands because there was no sound evidence for effectiveness.

\section{Future research}

We expect that this intervention might also be cost effective for older people with dementia without an informal care giver but who have the help of a

\section{Recommendations}

Well educated and well trained occupational therapists are needed to perform this complex community occupational therapy intervention (including occupational therapy diagnostics and specialised observation and interviewing skills, occupational therapy goal setting, and developing an effective treatment plan). Occupational therapists are best equipped to carry out the specific tasks, with the possible assistance of occupational therapy assistants or educated home care workers in future.

Community occupational therapy is a highly effective non-pharmacological therapy for older people with dementia and their care givers and not only improves the daily functioning of older people with dementia and their care givers' sense of competence ${ }^{9}$ but also improves the quality of life, mood, and health status of both patients and care givers, ${ }^{6}$ which are recommended as major outcomes in therapeutic research in dementia. ${ }^{41}$ As this community occupational therapy intervention was also cost effective we highly recommend it in all community health services, primary care services, and outpatient services for people with dementia and their care givers. Moreover, if the National Institute for Health and Clinical Excellence $(\mathrm{NICE})^{42}$ criteria for drug use were be applied to this intervention, implementation would be beyond all doubt. A multi-centred study would determine the cost effectiveness in different settings and healthcare regions.

We thank all participants for their contribution and Jana Zajec and Patricia Verstraten for occupational therapy treatments.

Contributors: All investigators were involved in the study design. MJLG was the lead investigator, developed the study design, acquired data, analysis, interpretations, and wrote the paper. EMMA, MJMV-D, JD, MGMOR, and WHLH were responsible for the design and supervision, and wrote the paper. LJ also wrote the paper. MT acquired data. MGMOR acquired data and is guarantor.

Funding: Fund VCVGZ, the Dutch Alzheimer Association with financial support of the Radboud University Nijmegen Medical Centre, and the

Dutch Occupational Therapy Association.

Competing interests: None declared.

Ethical approval: Medical ethics committee of the Radboud University Nijmegen Medical Centre of Nijmegen and Arnhem, No CWOM0012-0292. Provenance and peer review: Not commissioned; externally peer reviewed.

1 Wimo A, Jönsson B, Karlsson G, Winblad B. Health economics approaches to dementia. In: Wimo A, Karlsson G, Jönsson B, 
Winblad B, eds. The health economics of dementia. Chichester: John Wiley, 1998.

2 Wimo A, Winblad B, Aguero Torres $\mathrm{H}$, von Strauss E. The magnitude of dementia occurrence in the world. Alzheimer Dis Assoc Disord 2003;17:63-7.

3 Wimo A, Jonsson I, Winblad B. An estimate of the worldwide prevalence and direct costs of dementia in 2003. Dement Geriatr Cogn Disord 2006;21:175-81.

4 Meerding WJ, Bonneux L, Polder JJ, Koopmanschap MA, van der Maas PJ. Demographic and epidemiological determinants of healthcare costs in Netherlands: cost of illness study. BMJ 1998;317:111-5.

5 Jönsson L, Eriksdotter Jönhagen M, Kilander L, Soininen $\mathrm{H}$, Hallikainen M, Wimo A, et al. Determinants of costs of care for patients with Alzheimer's disease. Int J Geriatr Psychiatry 2006;21:449-59.

6 Graff MJL, Vernooij-Dassen MJM, Thijssen M, Dekker, J, Hoefnagel Whl, OldeRikkert MGM. Effects of community occupational therapy on quality of life, mood, and health status in dementia patients and their caregivers: a randomized controlled trial. J Gerontol A Biol Sci Med Sci 2007;62:1002-9.

7 Coen J. Dementia and caregiving. J Health Gain 1998;2:5-6.

8 Jepson C, Mc Corkle R, Adler D, Nuamah I, Lusk E. Effects of home care on caregivers' psychosocial status. Image J Nurs Sch 1999;31:115-20.

9 Graff MJL, Vernooij-Dassen MJM, Thijssen M, Dekker J, Hoefnagels WHL, OldeRikkert MGM. Community based occupational therapy in care givers of patients with dementia and their care givers: randomised controlled trial. BMJ 2006;333:1196.

10 Graff MJL, Vernooij-Dassen MJFJ, Zajec J, OldeRikkert, MGM, Hoefnagels WHL, Dekker J. How can occupational therapy improve the daily performance and communication of an older patient with dementia and his primary caregiver? Dementia 2006;5:503-32.

11 Ferri CP, Prince M, Brayne C, Brodaty H, Fratiglioni L, Ganguli M, et al. Global prevalence of dementia: a Delphi consensus study. Lancet 2005;366:2112-7.

12 Dutch Health Council. Gezondheidsraad. Rapport: dementie. Hague: Gezondheidsraad, 2002 (publication No 2002/04). (In Dutch.)

13 Slobbe LC], Kommer GJ, Smit JM, Groen J, Meerding WJ, Polder JJ. Kosten van Ziekten in Nederland 2003 [Costs of illnesses in the Netherlands 2003.] Bilthoven: RIVM, 2006. (In Dutch.)

14 RIVM. Rapport: Volksgezondheid Toekomst Verkenningen 2006. "Zorg voor Gezondheid". Kamerstuk, juli 2006 . [Health care explorations for the future 2006. "Care for health."]. Bilthoven: RIVM, 2006 (In Dutch.)

15 Raad voor de Volksgezondheid en Zorg (RVZ). Arbeidsmarkt en zorgvraag. Achtergrondstudies . [Labour market and care demand. Background studies.] Hague: RVZ, 2006. (In Dutch.)

16 Karlsson G, Wimo A, Jönsson B, Winblad B. Methodological issues in health economic studies of dementia. In: Wimo A, Karlsson G, Jonsson B, Winblad B, eds. Health economics of dementia . Chichester: John Wiley, 1998.

17 Gitlin LN, Corcoran M, Winter L, Boyce A, Hauck WW. A randomised, controlled trial of a home environment intervention: effect on efficacy and upset in caregivers and on daily function of persons with dementia. Gerontologist 2001;41:4-14.

18 Gitlin LN, Hauck WW, Dennis MP, Winter L. Maintenance of effects of the home environmental skill-building program for family caregivers and individuals with Alzheimer's disease and related disorders. Gerontol A Biol Sci Med Sci 2005;60:368-74.

19 Steultjens EMJ, Dekker J, Bouter L, Jellema S, Bakker, EB, vandenEnde CHM. Occupational therapy for community dwelling elderly people: a systematic review. Age Ageing 2004;33:453-60.

20 Graff MJL, Vernooij-Dassen MJFJ, Hoefnagels WHL, Dekker J, Witte de LP. Occupational therapy at home for older individuals with mild to moderate cognitive impairments and their primary care givers: a pilot study. Occup Ther J Res 2003;23:155-64.

21 Burgener SC, Bakas T, Murray C, Dunahee J, Tossey S. Effective caregiving approaches for patients with Alzheimer's disease. Geriatr Nurs 1998;19:121-6.
22 Hay J, LaBree I, Luo R, Clark F, Carlson M, Azen SP, et al. Costeffectiveness of preventive occupational therapy for independentliving older adults. I Am Ger Soc 2002;50:1381-8.

23 Knapp M, Thorgrimsen L, Patel A, Spector A, Hallam A, Orrel M, et al. Cognitive stimulation therapy for people with dementia: costeffectiveness analysis. Br J Psychiatr 2006;188:574-80.

24 Melis RJF, Adang EA, Teerenstra S, van Eijken MIJ, Wimo A, Achterberg T, et al. The cost-effectiveness of a multidisciplinary intervention model for community-dwelling frail older people. Gerontol A Biol Sci Med Sci (in press).

25 Brodaty H, Peters KE. Cost effectiveness of a training program for dementia carers. Int Psychogeriatr 1991;3:11-22.

26 American Psychiatric Association (APA). Diagnostic and statistical manual of mental disorders . 4th edn. Washington, DC: American Psychiatric Association, 1994.

27 Reisberg B, London $\mathrm{E}$. The brief cognitive rating scale. Language, motoric and mood concomitants in primary degenerative dementia. Psychopharmacol Bull 1983;19:702-8.

28 Brink TL, Yesavage JA, Lum O, Heersema P, Adey MB, Rose TL. Screening tests for geriatric depression. Clin Gerontol 1982;1:37-43.

29 Graff MJL, Melick van MBM. Het ontwikkelen, testen en implementeren van een ergotherapeutische standaard. De standaard voor de ergotherapeutische diagnostiek en behandeling van geriatrische patiënten met niet-ernstige cognitieve stoornissen. [The development, testing and implementation of an occupational therapy guideline. The guideline for the OT diagnosis and treatment of older persons with cognitive impairments.] Ned Tijdschr Ergother 2000;28:169-74. (In Dutch.)

30 Fisher AG. Assessment of motor and process skills . Fort Collins, CO: Three Stars Press, 2003.

31 Teunisse S, Derix MM. The interview for deterioration in daily activities in dementia: agreement between primary and secondary caregivers. Int Psychogeriatr 1997;9(suppl 1):155-62.

32 Vernooij-Dassen MJM, Persoon JM, Felling AJ. Predictors of sense of competence in caregivers of demented persons. Soc Sci Med 1996;43:41-9.

33 Miller MD, Paradis CF, Houck PR, Mazumdar S, Stack JA, Rifai AH, et al. Rating chronic medical illness in burden in psychogeriatric practice and research: application of the cumulative illness rating scale. Psychiatry Res 1992;41:237-48.

34 Teri L, Truax P, Logsdon R, Uomoto J, Zarit S, Vitaliano PP, et al. Assessment of behavioral problems in dementia: the revised memory and behavior problems checklist. Psychology Aging 1992;7:622-31.

35 Teunisse S. Clinimetrics in dementia . Enschede, Netherlands: PrintPartners Ipskamp, 1997.

36 Radloff LS. The CES-D scale: a self-report depression scale for research in the general population. Appl Psychol Meas 1997;1:385-401.

37 Drummond MF, O'Brien B, Stoddart GL, Torrance GW. Methods for the economic evaluation of health care programmes. Oxford: Oxford Medical Publications, 1997.

38 Oostenbrink JB, Koopmans MA, Rutten FFH. Handleiding voor kostenonderzoek. Methoden en richtlijnen voor economische evaluaties in de gezondheidszorg. [Guideline for cost evaluation.] Amsterdam: College voor Zorgverzekeringen (CVZ), 2004. (In Dutch.)

39 Dutch Occupational Therapy Association. NVE. Richtlijn voor declaraties verrichtingen Eerstelijns Extramurale Ergotherapie (EEE). [Guideline for the declaration of community occupational therapy visits.] Utrecht: NVE, 2006. (In Dutch.)

40 Siemonsma PC, Walker MF. Practical guidelines for independent assessment in randomized controlled trials (RCTs) of rehabilitation. Clin Rehabil 1997;11:273-9.

41 Rockwood K, Gauthier S. Trial designs and outcomes in dementia therapeutic research . London: Taylor \& Francis, 2006.

42 Maynard A. Transparency in health technology assessments. BM 2007;334:594-5.

Accepted: 4 November 2007 